\title{
Predator identity and recruitment of coral-reef fishes: indirect effects of fishing
}

\author{
Christopher D. Stallings* \\ Department of Zoology, Oregon State University, Corvallis, Oregon 97331, USA \\ Present address: Florida State University Coastal and Marine Laboratory, St. Teresa, Florida 32358, USA
}

\begin{abstract}
Studies of food and interaction webs are often simplified by combining different species of predator into guilds, especially predators that are closely related. Such combinations require the assumption that predators are functionally redundant or at least have similar effects on prey abundances and community structure. However, few studies have rigorously tested this assumption, particularly with exploited species of marine predators. Moreover, fishing can strongly alter the relative abundances of different predatory species, further highlighting the need to examine the top-down effects of different predators on lower trophic-level species within marine communities. Throughout the greater Caribbean, intensive fishing has depleted populations of Nassau grouper Epinephelus striatus, while populations of the less-targeted coney Cephalopholis fulva have proliferated. In the present study I experimentally tested the effects of these different grouper species on recruitment of other coral-reef fishes to spatially isolated reefs. Recruitment to reefs occupied by Nassau grouper was similar to that on predator-free control reefs, and both treatments accumulated higher relative recruit abundance and diversity than reefs occupied by coney. Thus, even closely related predator species can have substantially different effects on lower trophic levels. Shifts in dominance of predatory species may therefore lead to dramatic changes to prey communities. These findings underscore the importance of addressing both the direct and indirect effects of fishing on marine communities.
\end{abstract}

KEY WORDS: Ecosystem-based management $\cdot$ Field experiment $\cdot$ Fishing $\cdot$ Food web $\cdot$ Functional diversity $\cdot$ Grouper $\cdot$ Predation $\cdot$ Recruitment

Resale or republication not permitted without written consent of the publisher

\section{INTRODUCTION}

Predation is an important process regulating prey populations (Hixon et al. 2002) and structuring ecological communities (Paine 1966). Although much experimental work has been conducted on the effects predatory marine fishes have on lower trophic-level species (review by Hixon \& Jones 2005), the approach has typically been to manipulate either predator presence or density, without regard to predator identity beyond particular piscivorous guilds. Grouping predators in this way requires the assumption that higher trophiclevel species have substitutable effects (i.e. are functionally redundant) in their ecological communities (Lawton \& Brown 1993). Although this assumption sim- plifies investigations, it cannot provide insight into how different species within guilds affect populations and communities.

Species often assumed to exhibit similar ecological functions can have very different effects on the communities to which they belong. Indeed, a growing body of literature from both theoretical (e.g. Loreau 2004) and experimental (e.g. Chalcraft \& Resetarits 2003) studies provides evidence that functional redundancy (also termed functional equivalence) is rare or absent in natural ecosystems. However, many investigations demonstrating a lack of functional redundancy have focused on study species from broadly defined taxonomic groups that differ in morphological attributes (e.g. fish versus crab predators in marine systems, fish versus 
amphibian predators in aquatic systems), and experimental trials are commonly performed in laboratory aquaria. Disentangling independent effects of closely related, morphologically similar marine predators that share common habitat and diet requirements (e.g. confamiliars) has received far less attention, particularly in their natural habitats. Investigating differences in the predatory impact of marine fishes not only increases our understanding of their functional roles in coastal ecosystems, but may also provide a better understanding of the ecological consequences of changes to predatory fish communities (e.g. extirpations, introductions; Bruno \& Cardinale 2008, Heithaus et al. 2008).

Overexploitation has depleted populations of predatory fish species worldwide (Jackson et al. 2001, Myers \& Worm 2003). Large-bodied predators have been particularly vulnerable to fishing and are commonly replaced with smaller, often less-targeted predators (Pauly et al. 1998, Ward \& Myers 2005). In the Caribbean, the biomass of predatory fishes on coral reefs has been reduced (Mora 2008) and the structure of their communities has become dominated by small-bodied predators in both back- and fore-reef habitats with increased anthropogenic impacts (Stallings in press). For example, it is well documented that both abundance and biomass of small-bodied groupers (i.e. Cephalopholis spp.) increase in areas where fishing reduces that of large-bodied groupers (e.g. Epinephelus spp., Mycteroperca spp.) (Chiappone et al. 2000). A shift to smaller predators may have top-down effects on abundances of other fishes and community structure, and could potentially have unanticipated impacts (Jackson et al. 2001, Carr et al. 2002), but data are lacking for marine predatory fishes.

In the present study, I experimentally tested the relative effects of a large-bodied, intensively fished piscivore (Nassau grouper Epinephelus striatus) and a smaller, less-targeted piscivore (coney Cephalopholis fulva) on recruitment of coral-reef fishes. Previous research suggests the 2 species have substantial overlap in both habitat use of shallow patch reefs (Beets \& Hixon 1994) and diet (Randall 1967, Heemstra \& Randall 1993). In fact, Nassau grouper, coney, and other confamilars have been used interchangeably in field experiments testing the influence of groupers on the abundance of their fish prey (i.e. assumed functional redundancy). However, experimental studies involving multiple serranids were typically designed to investigate general predatory effects and either intentionally combined them into a single predatory treatment (Hixon \& Carr 1997, Almany 2003, 2004) or did not control for the presence of other resident predators (Eggleston et al. 1997). The relative effects of individual species of grouper on prey abundance and community structure have therefore remained untested.

\section{MATERIALS AND METHODS}

Study site. I conducted the present study using SCUBA on a matrix of isolated coral patch reefs located on a shallow sand and seagrass flat ( 3 to $5 \mathrm{~m}$ deep) near the Caribbean Marine Research Center, Lee Stocking Island, Bahamas. The reefs had been translocated to their present locations by Hixon \& Carr (1997) approximately 10 yr before the present study and were standardized for size (area, mean $\pm \mathrm{SD}=6.6 \pm 1.0 \mathrm{~m}^{2}$ ), structural complexity, and distance between reefs $(200 \mathrm{~m})$. The nearest naturally occurring reef was located $>1.0 \mathrm{~km}$ from the edge of the matrix.

Study species. Nassau grouper are large (max. total length $\left[\mathrm{TL}_{\max }\right]=122 \mathrm{~cm}$ ) members of the Family Serranidae, historically distributed throughout the greater Caribbean region (Heemstra \& Randall 1993). Latestage larvae settle to a range of habitats including macroalgal flats, artificial and natural patch reefs, and rubble (Eggleston 1995, Colin et al. 1997). Nassau grouper that settle to non-patch reef habitats (e.g. macroalgal flats) later move onto them as juveniles at approximately $15 \mathrm{~cm}$ TL (Eggleston 1995, Dahlgren \& Eggleston 2000), and finally to fore-reefs as adults at sizes between 30 and $40 \mathrm{~cm}$ TL (C. P. Dahlgren \& M. A. Hixon unpubl. data). Diets of Nassau grouper consist of both benthic invertebrates (crabs and other crustaceans) and fishes, the latter becoming more prevalent as individuals grow $>20 \mathrm{~cm}$ TL (Randall 1967, Eggleston et al. 1998). Nassau grouper first become piscivorous at approximately $15 \mathrm{~cm}$ TL (Eggleston et al. 1997).

Coney are smaller serranids $\left(\mathrm{TL}_{\max }=41 \mathrm{~cm}\right)$, also distributed throughout the greater Caribbean region (Heemstra \& Randall 1993). Like Nassau grouper, latestage larvae settle to a range of habitats, including rubble and both artificial and natural patch reefs (pers. obs.). Compared with Nassau grouper, less is known about ontogenetic movements of coney. However, larger individuals may immigrate to fore-reef habitats, as evidenced by their high abundances there (pers. obs.). Also like Nassau grouper, diets of coney consist of benthic invertebrates and fishes (Randall 1967). Field observations suggest that coney may be voraciously piscivorous at a much smaller size than Nassau grouper: individuals as small as $5 \mathrm{~cm}$ TL actively hunt and consume other fishes (pers. obs., D. W. Johnson unpubl. data).

Given the similarities in both habitat use and diet, ecological interactions between Nassau grouper and coney are to be expected. Indeed, field observations revealed their natural abundances to be negatively correlated with one another $(r=-0.17)$ (C. D. Stallings unpubl. data), suggesting the presence of negative interactions between the groupers. There is also evi- 
dence from both stomach contents (Randall 1967) and laboratory mesocosms (C. D. Stallings unpubl. data) that Nassau grouper eat coney. In addition, aggressive behavior by Nassau grouper on coney causes the latter to become more vigilant when the former is present in high abundances (Stallings 2008).

Experimental design. To investigate the relative effects of Nassau grouper and coney on recruitment of other coral-reef fishes, I manipulated their presence on 18 of the translocated patch reefs. I assigned 6 reefs to each of 3 treatments: Nassau grouper only, coney only, or no grouper (control). The grouper treatments were established to reflect natural, pre-manipulation abundances (Nassau grouper $=2$ fish per reef; coney $=1$ fish per reef). Coney (TL, mean $\pm \mathrm{SD}=15.5 \pm 3.4 \mathrm{~cm}$, range $=11$ to $19 \mathrm{~cm}$ ) were added to reefs as needed. Previous efforts had shown that Nassau grouper cannot be effectively added to the experimental reefs because of strong homing behavior (M. A. Hixon unpubl. data), but they can be removed by translocating them at least several kilometers (Eggleston et al. 1997). I therefore randomly selected reefs from those that had at least 2 Nassau grouper present (21 of the 32 reefs). Although this logistical constraint reduced the number of reefs possible for the Nassau grouper treatment, I did not detect any spatial patterns of Nassau grouper abundance or distribution across the entire matrix (i.e. they were randomly distributed). I selectively removed Nassau grouper from the reefs as needed so that the 2 remaining individuals were of 2 size classes. The larger size class $(\mathrm{TL}$, mean $=25.3 \pm 1.2 \mathrm{~cm}$, range $=24$ to $27 \mathrm{~cm}$ ) included fish that reportedly have increased proportions of fish in their diets (Eggleston et al. 1998). The smaller of the 2 Nassau grouper were individuals that had probably recently moved onto the patch reefs $(\mathrm{TL}$, mean $=16.5 \pm 1.2 \mathrm{~cm}$, range $\mathrm{TL}=15$ to $18 \mathrm{~cm})$, and were of similar size to the coney $\left(t_{10}=0.679, \mathrm{p}=0.512\right)$. These 2 size classes were chosen to maximize the potential to detect the effects of Nassau grouper on fish recruitment, if they in fact existed.

Prior to all grouper manipulations, I standardized the fish communities on the experimental reefs by removing all resident piscivores with diets consisting of $\geq 10 \%$ fishes (Randall 1967), including moray eels, snappers, and cardinalfishes. I also removed all territorial damselfish (Pomacentridae; adults and new recruits), which can be strong interference competitors with coral-reef fish recruits (Carr et al. 2002, Almany 2003). Naturally low abundances of grunts (Haemulidae) and gobies (Gobiidae) were evenly distributed across treatments, but were not removed because I assumed the effects of these invertivores on recruitment of other fishes to be negligible. All fish manipulations were maintained for the duration of the study (i.e. 'press experiment'). Although experimental groupers were not individually tagged, their sizes, color (e.g. coney have multiple color phases), and natural markings were noted for consistency during surveys conducted every $4 \mathrm{~d}$. Both species exhibited high site fidelity and only one individual (coney) required replacement during the experiment. Removals were conducted using the fish anesthetic quinaldine and hand nets. Fish removed from the experimental reefs were released unharmed on reefs sufficiently distant to inhibit homing. Removed Nassau grouper were placed on natural reefs located $\sim 3 \mathrm{~km}$ from the experimental reefs, on the opposite side of a tidal cut that served as an effective barrier to homing.

The experiment ran for $52 \mathrm{~d}$ between June and August 2004, these summer months being when recruitment of coral-reef fishes tends to be highest in the Bahamas (Thorrold et al. 1994). Once the treatments were established, I conducted recruit censuses on each experimental reef every $4 \mathrm{~d}$. I counted all recruits (i.e. both newly settled and previously recruited fish) of all species to allow calculation of cumulative recruitment to each reef. Conspicuous species were first identified by the diver from a distance of 1 to $3 \mathrm{~m}$ away from the reef. Cryptic species were then counted using 2 techniques: (1) shining a flashlight into all reef holes and crevices to identify hiding species and (2) the diver running a hand over all reef surfaces to cause movement of species which rely on camouflage tactics. I assumed that the supply of recruits (i.e. via settlement to the reefs) was even across treatments and did not vary spatially across the reef matrix, as indicated by previous studies of the same matrix of reefs (Almany 2003, 2004).

Statistical analysis. I compared cumulative fish recruitment among the grouper treatments at both the community and species levels. At the community level, I measured treatment effects on final recruit species diversity using 3 indices: (1) richness $(S$, the total number of species), (2) the Simpson's diversity index $(D=$ $1-\Sigma p_{i}^{2}$ ) which is not strongly affected by rare species, and (3) rarified richness to adjust for differences in recruit abundances among treatments. I compared diversity between treatments using 2-sample $t$-tests with Bonferroni corrections for multiple comparisons $\left(\alpha^{\prime}=0.05 / 3=0.017\right)$.

At the species level, I compared temporal changes in cumulative fish recruit abundance of common species ( $\geq 1 \%$ total observations) using a linear mixed effects model (LMEM; S-Plus 6.2 LME). Excluding the mean and error terms, the model was:

$$
\begin{aligned}
\text { Abundance }= & \text { Treatment }+ \text { Time }+(\text { Treatment } \times \text { Time }) \\
& + \text { Reef }(\text { Treatment })+\gamma
\end{aligned}
$$

with Treatment and Time as fixed factors. Reef was included in the model as a blocking factor to accommo- 
date within-reef temporal structure of the repeated measures data. The gamma term $(\gamma)$ was specified as first order autocorrelation to correct the temporal structure of the cumulative recruit abundance response (i.e. correlation between time $t+1$ and time $t$ ). The interaction term describes the trajectory of each grouper treatment over time, and is the appropriate test of treatment effects. Because each reef was a replicate of a given treatment, the treatment term was tested over the blocking factor, and all other terms were tested over the error.

\section{RESULTS}

\section{Recruit communities}

A total of 35 coral-reef fish species recruited to the experimental reefs, of which 27 were rare (each $<1 \%$ of total abundance). The abundances of 4 rare wrasses (Labridae) of the genus Halichoeres (H. garnoti, $H$. maculipinna, $H$. pictus, and $H$. radiatus) were combined into a single response group. The 9 most common species comprised $97 \%$ of the total observations.

The abundances of fish recruits were indistinguishable among treatments at the beginning of the experiment. Within about a week, however, total recruit abundance on control reefs and those occupied by Nassau grouper was greater than that on reefs with coney (Fig. 1). Final recruit abundance (Day 52) was 2.7 times higher on both Nassau grouper reefs $\left(t_{10}=\right.$ 5.27, p < 0.001) and control reefs $\left(t_{10}=6.05, \mathrm{p}<0.001\right)$ than on coney reefs.

The species diversity of recruits at the end of the experiment was higher on reefs occupied by Nassau

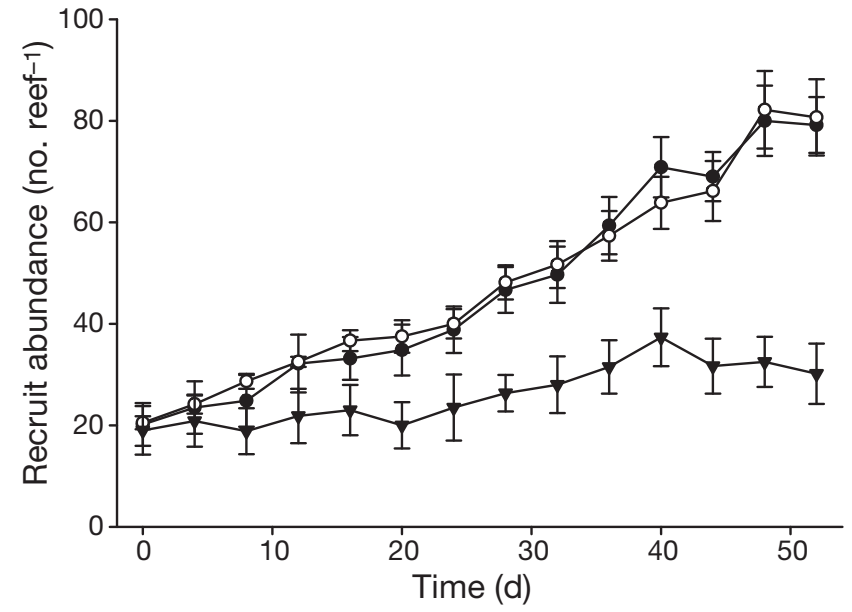

Fig. 1. Temporal changes in total abundance (mean $\pm \mathrm{SE}$ ) of fish recruits on reefs occupied by different species of grouper.

$(\bullet)$ control reefs; (O) Nassau grouper reefs; ( $\mathbf{\nabla})$ coney reefs

grouper and on control reefs than on reefs occupied by coney (Fig. 2a,b). No differences were detected between controls and Nassau grouper reefs. Higher species richness $(S)$ on both Nassau grouper reefs $\left(S[\right.$ mean $\left.\pm \mathrm{SD}]=9.83[0.477], t_{10}=1.88, \mathrm{p}=0.045\right)$ and control reefs ( $S=10.00$ [0.258], $\left.t_{10}=2.31, \mathrm{p}=0.022\right)$ was marginally significant (after correction, $\alpha^{\prime}=0.017$ ) compared with coney reefs $(S=8.17$ [0.749]). Simpson's index of diversity $(D)$ was higher on both Nassau grouper reefs $\left(D=0.851\right.$ [0.005], $\left.t_{10}=3.25, \mathrm{p}=0.004\right)$ and on control reefs $\left(D=0.834[0.008], t_{10}=2.48, \mathrm{p}=\right.$ $0.016)$ than on coney reefs $(D=0.768$ [0.025]). Rarefied species richness at 30 individuals (the average number of recruits on coney reefs) did not differ between treatments (Fig. 2c), indicating that differences in diversity were driven by differences in overall abundance.
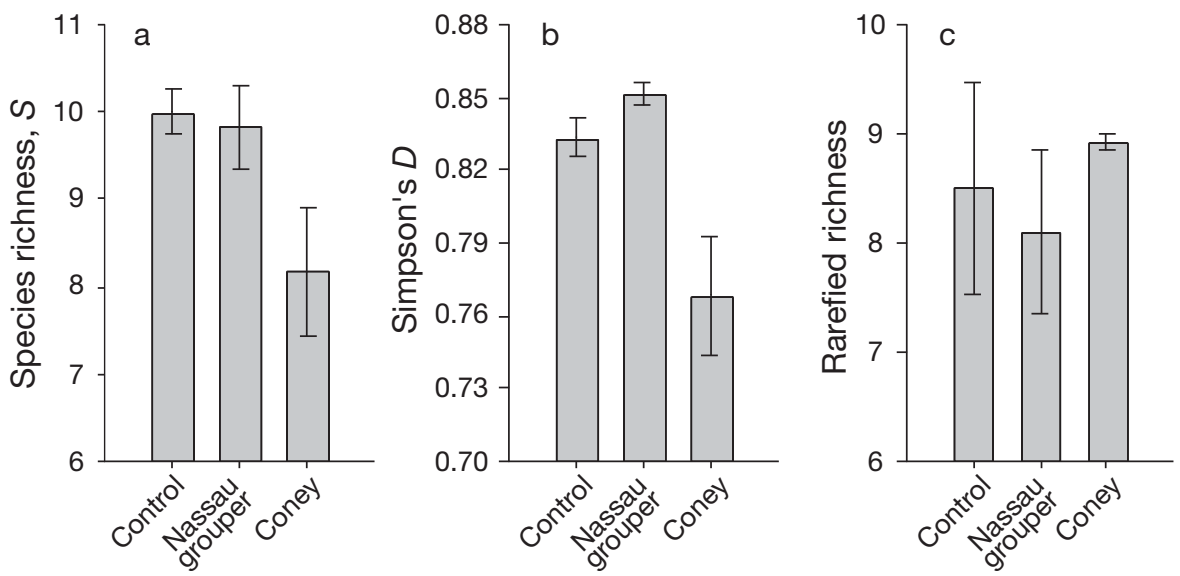

Fig. 2. Recruit diversity (mean \pm SE) among treatments at the end of the experiment. (a) Species richness, (b) Simpson's diversity index, and (c) rarefied richness at 30 individuals 


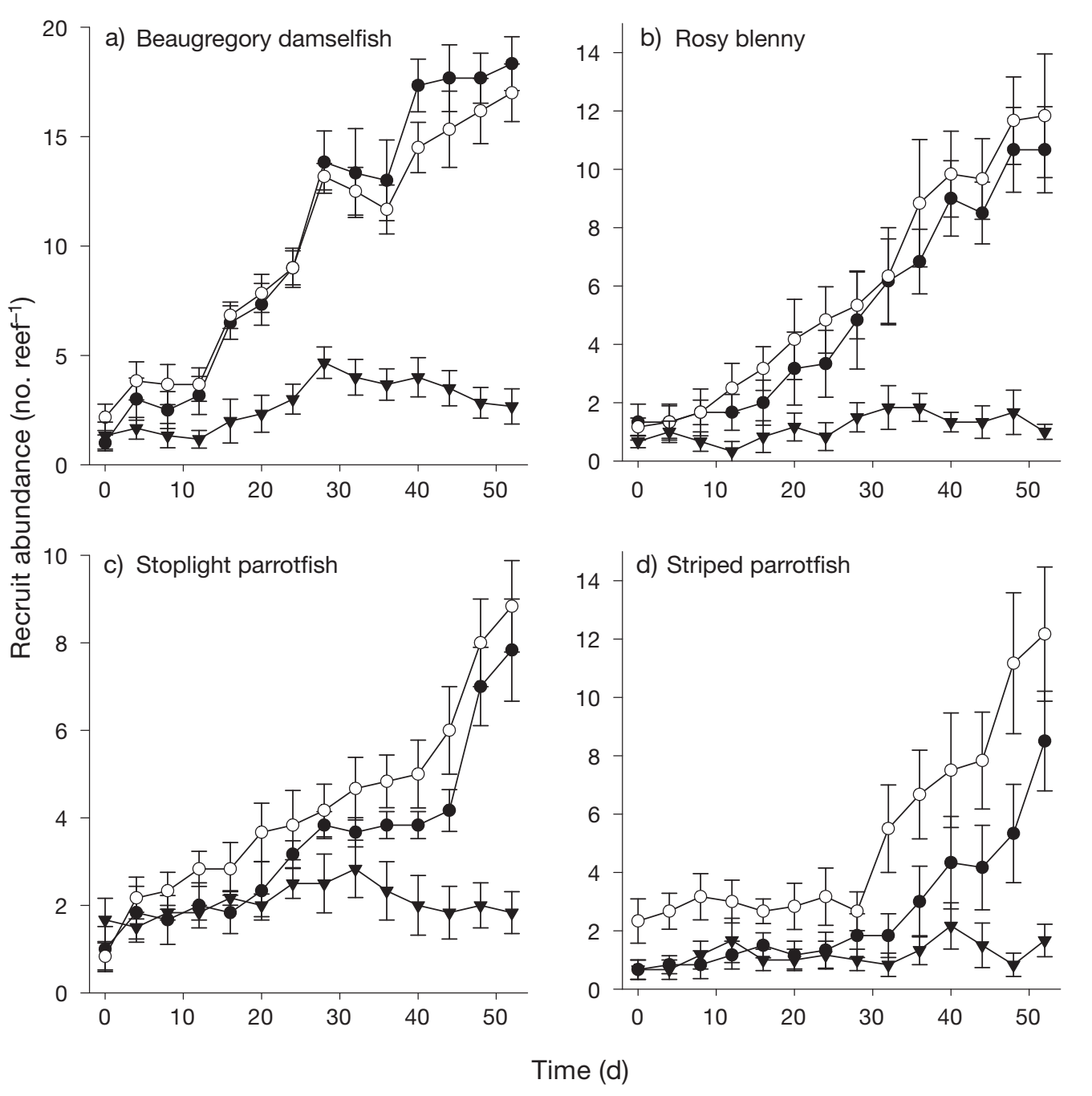

Fig. 3. Temporal changes in cumulative recruit abundance (mean \pm SE) of 4 common species: (a) beaugregory damselfish Stegastes leucostictus, (b) rosy blenny Malacoctenus macropus, (c) stoplight parrotfish Sparisoma viride, and (d) striped parrotfish Scarus iserti. ( $\bullet$ control reefs; (O) Nassau grouper reefs; $(\mathbf{\nabla})$ coney reefs

\section{Recruit species-level comparisons}

Cumulative recruitment between the Nassau grouper and control treatments did not differ; therefore I report only comparisons between the 2 grouper treatments. Recruitment of 4 species was higher on Nassau grouper and control reefs than on coney reefs (Table 1). These 4 species were among the most abundant to recruit to the experimental reefs (i.e. each contributed $>10 \%$ total observations), and were beaugregory damselfish Stegastes leucostictus (Pomacentridae $\left.t_{154}=7.32, \mathrm{p}<0.001\right)$, rosy blenny Malacoctenus macropus (Labrisomidae; $t_{154}=5.37, \mathrm{p}<0.001$ ), striped parrotfish Scarus iserti (Scaridae; $t_{154}=4.09, \mathrm{p}=0.001$ ), and stoplight parrotfish Sparisoma viride (Scaridae; $t_{154}=5.60, \mathrm{p}<0.001$ ) (Fig. 3). Cumulative recruitment of 2 gobiids, bridled goby Coryphopterus glau- cofraenum and goldspot goby Gnatholepis thompsoni, was also high, but no differences were detected between treatments for these cryptic species. Cumulative recruitment of 3 other common species, bluehead wrasse Thalassoma bifasciatum (Labridae), bicolor damselfish Stegastes partitus (Pomacentridae), and the Halichoeres species group (Labridae), was lower than the other 6 species, and no differences were detected among treatments.

\section{DISCUSSION}

The goal of the present study was to examine how different predators typically assumed to have similar functional roles affect recruitment of lower trophiclevel species. Predator identity was clearly an impor- 
tant factor, with 2 species of grouper having remarkably different effects on populations and communities of recruiting coral-reef fishes. Coney had very strong, direct, negative effects on recruitment of other fishes, resulting in local communities with relatively low diversity and abundance compared to grouper-free control reefs. Nassau grouper did not have any detectable direct effects on recruitment of other fishes, resulting in local communities indistinguishable from control reefs lacking predators.

Although not directly tested in the field experiment, predation by coney was the likely mechanism that reduced recruitment of other fishes. Settling fishes do not avoid reefs occupied by coney (Almany 2003) and coney can be voraciously piscivorous on settlementsized fishes in the field (White 2007, Stallings 2008). Among the 9 species comprising $97 \%$ of total observations, coney reduced recruitment for the most common, conspicuous species (i.e. beaugregory damselfish, rosy blenny, stoplight parrotfish, and striped parrotfish). Although bridled and goldspot gobies were present in high abundances, both species are cryptically colored and remain close to the substratum; recruitment of neither species was affected by coney. Likewise, I was unable to detect a predatory effect of coney on 3 conspicuous species (bicolor damselfish, bluehead wrasse, and the Halichoeres wrasses) that recruited at relatively low abundances. However, coney have been shown to be effective predators on both bluehead and Halichoeres wrasses (White 2007, Stallings 2008), as well as bicolor damselfish (D. W. Johnson unpubl. data), when prey are present at relatively high abundances. No differences in rarefied richness between treatments (Fig. 2c) indicated that predation by coney was not selective on any particular species. Reduced species richness at the end of the experiment on coney reefs was therefore due to their strong negative effect on overall recruit abundance, particularly among species that were both conspicuous and abundant.

Neither of the 2 size classes of Nassau grouper used in this experiment negatively affected recruitment (i.e. no difference between reefs with Nassau grouper and control reefs lacking predators). Although experimental treatments involving multiple predators can result in nonlinear effects on prey abundance, including decreased per capita predation rates through interference (Sih et al. 1998), no previous study has demonstrated intraspecific interference strong enough to completely remove a predatory effect on prey when it in fact exists (Vance-Chalcraft et al. 2007). Therefore the most parsimonious explanation for no measureable effect of Nassau grouper on recruitment of coralreef fishes is that the former does not prey upon the latter and predator interference was either minor or did not exist.

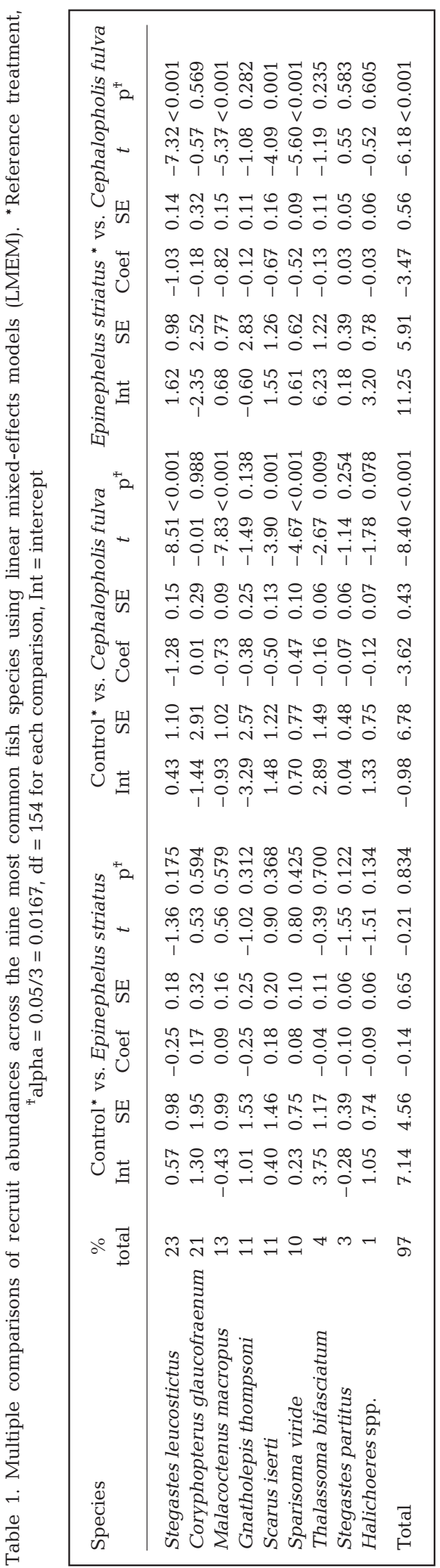


Nassau grouper $>30 \mathrm{~cm}$ TL consume increasing proportions of fish compared to the size classes examined here (Randall 1967, Eggleston et al. 1998), but piscivores of such size are unlikely to target small fish recruits ( 1.5 to $3.0 \mathrm{~cm}$ TL). In a separate experiment that included a greater range of Nassau grouper sizes and abundances, I did not detect a negative effect of groupers $>30 \mathrm{~cm}$ TL on recruitment (Stallings 2008). Eggleston et al. (1997) was also unable to detect a predatory effect by Nassau grouper on fishes 1 to $3 \mathrm{~cm}$ $\mathrm{TL}$, but did find a weak, albeit significant, effect on fishes 4 to $10 \mathrm{~cm}$ TL. Recruit communities in the present study were dominated by fishes $\leq 3 \mathrm{~cm}$ and newly settled fish are more vulnerable to predation than juveniles and adults (Almany \& Webster 2006), possibly because older fish have lived in the reef environment long enough to acquire predator avoidance behaviors (Almany 2004). The relative effects of piscivory by large Nassau grouper on older juvenile and adult fishes versus that of the relatively small coney on recruits remain untested, but could provide a test of the community level effects of a few, large predators versus that of abundant but smaller ones (e.g. Chalcraft \& Resetarits 2004).

Differences in the predatory effect of Nassau grouper found by Eggleston et al. (1997) (negative effect) from that in the present study (no effect) may have also been due to differences in the habitats used in each study. Eggleston et al. (1997) used low-relief artificial reefs constructed of concrete slabs supported by PVC pipes that were designed to simulate dens (casitas) for Caribbean spiny lobster Panulirus argus (Eggleston \& Lipcius 1992). The habitat setting of the present study involved patch reefs of translocated coral (see 'Materials and methods') that were designed to simulate natural patch reefs. The translocated coral reefs retain the same structural configuration as natural coral reefs with a variety of hole sizes and growth forms, which can influence the composition, diversity and abundance of reef fishes (Carr \& Hixon 1997). Translocated coral reefs have supported similar communities of fishes as natural reefs in other systems (Yap 2009), and 15 yr of census data in the Bahamas indicate that fish communities on natural patch reefs are more similar to that on the experimental reefs used in the present study than on artificial reefs constructed of concrete building materials (C. D. Stallings et al. unpubl. data). Pre- and post-settlement processes of coral reef fishes apparently differ between artificial reefs constructed of building materials versus those constructed of translocated corals, which highlights the importance of experimental venue when designing studies as well as clearly defining the goals of restoration with artificial reefs (e.g. to support fisheries versus tourism).
Differential predation by individual piscivore species found in the present study reveals complexity in the food web that may be oversimplified by grouping predators into a single guild. Although combining species simplifies experiments and discussions of food and interaction webs, the present study highlights the potential shortcomings of assuming that predators can be categorized into functionally similar groups, even regarding predatory species from the same family. Arguments have been made against grouping species because it does not allow detection of important species-level effects in food webs (Polis \& Strong 1996). Recent experiments involving multiple predators support the conclusions here that species identity can strongly influence predatory effects on lower trophiclevel prey, often stronger than predator diversity (e.g. Chalcraft \& Resetarits 2003, O'Connor et al. 2008). In addition to indicating functional redundancy may be less common than previously expected, these findings underscore the importance of understanding ecosystem responses to changes in predator communities.

Nassau grouper have been intensely fished throughout their range and are now ecologically extinct throughout much of the greater Caribbean region (Stallings in press). Observational studies have indicated that both abundance and biomass of smaller groupers, including coney, increase in areas where that of Nassau grouper is reduced (Chiappone et al. 2000), probably due to moderated interactions between the 2 species. In a separate experiment, coney became more vigilant, grew at slower rates, and had reduced impacts on recruit communities when Nassau grouper were present at high abundances (Stallings 2008). Fig. 4 is a food-web model depicting the relative effects of fishing on Nassau grouper and coney and the experimentally tested effects of these predators on recruitment of coral-reef fishes. This model describes a

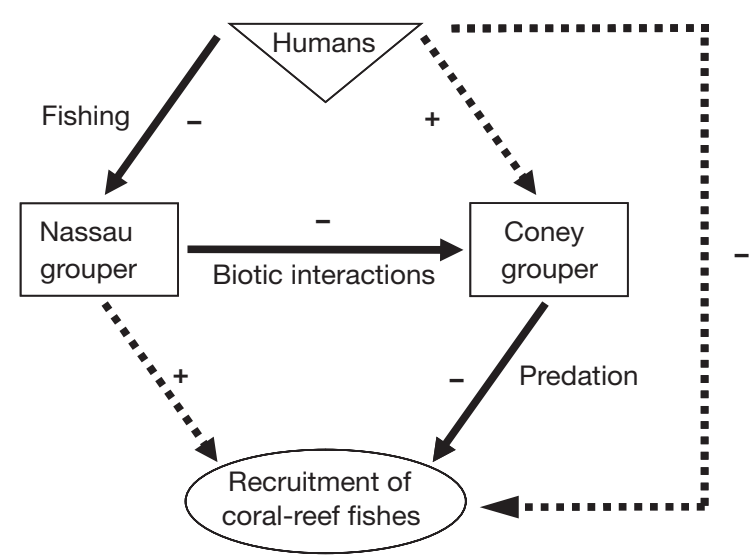

Fig. 4. Model of direct (solid arrows) and indirect (dashed arrows) effects of fishing on predatory groupers and recruitment of coral-reef fishes in a Bahamian food web 
potential indirect effect of fishing on both predators and lower trophic levels. Fishing clearly has a direct negative effect on Nassau grouper populations, but also has an indirect positive effect on coney populations and, consequently, an indirect negative effect on recruitment of other fishes (Fig. 4).

Shifts in biomass from large to small predators have been reported in other intensely fished marine ecosystems (e.g. Pauly et al. 1998, Jackson et al. 2001, Ward \& Myers 2005) and can have cascading effects on lower trophic-level species (Dulvy et al. 2004). Increased abundance of mid-level predators may have deleterious effects on fish diversity and community structure, with important implications for ecosystem functioning, stability, goods, and services (Solan et al. 2006 and contributions within). For example, reduced abundance of herbivorous parrotfishes documented here could result in increased macroalgal cover and decreased cover of foundation-forming corals (Mumby et al. 2007), with possible implications for alternating stable states (Knowlton 2004); however, such predictions may also be too simplistic to account for the complex ecosystem responses to predator loss (Bruno \& Cardinale 2008). In light of these considerations, it is imperative to understand the effects of fishing on marine ecosystems beyond the obvious reductions in biomass of fished species (Duffy et al. 2007). Holistic approaches to management and conservation efforts, such as ecosystem-based fisheries management and marine reserves, may be strengthened by understanding and addressing both direct and indirect effects of fishing and the independent roles of individual predators (Francis et al. 2007).

Acknowledgements. I thank J. Noell, N. R. Ehlers, M. R. Christie, M. A. Hixon, and D. W. Johnson for their assistance in the field, and M. A. Hixon and M. H. Carr for use of the experimental reefs. Various aspects of this study benefited from discussions with M. J. Stallings, C. P. Dahlgren, S. D. Hacker, and C. Syms. This paper is a chapter from my dissertation, which benefited from comments by my doctoral committee-M. A. Hixon (chair), S. A. Heppell, B. A. Menge, P. A. Murtaugh, and A. W. Stoner-and by D. W. Johnson, G. Von Glavenvich, R. N. Lipcius, and 3 anonymous reviewers. Financial support was provided by the National Undersea Research Program, courtesy of the Caribbean Marine Research Center, and NSF grants OCE-00-93976 and OCE05-50709 to M. A. Hixon, as well as a Thompson Fellowship and salary from the Florida State University Coastal and Marine Laboratory during preparation of the manuscript to the C.D.S.

\section{LITERATURE CITED}

Almany GR (2003) Priority effects in coral reef fish communities. Ecology 84:1920-1935

Almany GR (2004) Differential effects of habitat complexity, predators and competitors on abundance of juvenile and adult coral reef fishes. Oecologia 141:105-113
Almany GR, Webster MS (2006) The predation gauntlet: early post-settlement mortality in reef fishes. Coral Reefs 25: $19-22$

Beets J, Hixon MA (1994) Distribution, persistence, and growth of groupers (Pisces: Serranidae) on artificial and natural patch reefs in the Virgin Islands. Bull Mar Sci 55: 470-483

Bruno JF, Cardinale BJ (2008) Cascading effects of predator richness. Front Ecol Environ 6:539-546

Carr MH, Hixon MA (1997) Artificial reefs: the importance of comparisons with natural reefs. Fisheries 22:28-33

Carr MH, Anderson TW, Hixon MA (2002) Biodiversity, population regulation, and the stability of coral-reef fish communities. Proc Natl Acad Sci USA 99:11241-11245

Chalcraft DR, Resetarits WJ (2003) Predator identity and ecological impacts: Functional redundancy or functional diversity? Ecology 84:2407-2418

Chalcraft DR, Resetarits WJ (2004) Metabolic rate models and the substitutability of predator populations. J Anim Ecol 73:323-332

Chiappone M, Sluka R, Sealey KS (2000) Groupers (Pisces: Serranidae) in fished and protected areas of the Florida Keys, Bahamas and northern Caribbean. Mar Ecol Prog Ser 198:261-272

Colin PL, Laroche WA, Brothers EB (1997) Ingress and settlement in the Nassau grouper, Epinephelus striatus (Pisces: Serranidae), with relationship to spawning occurrence. Bull Mar Sci 60:656-667

Dahlgren CP, Eggleston DB (2000) Ecological processes underlying ontogenetic habitat shifts in a coral reef fish. Ecology 81:2227-2240

> Duffy JE, Carinale BJ, France KE, McIntyre PB, Thebault E, Loreau M (2007) The functional role of biodiversity in ecosystems: incorporating trophic complexity. Ecol Lett 10:522-538

Dulvy NK, Freckleton RP, Polunin NVC (2004) Coral reef cascades and the indirect effects of predator removal by exploitation. Ecol Lett 7:410-416

> Eggleston DB (1995) Recruitment in Nassau grouper Epinephelus striatus: post-settlement abundance, microhabitat features, and ontogenetic habitat shifts. Mar Ecol Prog Ser 124:9-22

> Eggleston DB, Lipcius RN (1992) Shelter selection by spiny lobster under variable predation risk, social conditions, and shelter size. Ecology 73:992-1011

- Eggleston DB, Lipcius RN, Grover JJ (1997) Predator and shelter-size effects on coral reef fish and spiny lobster prey. Mar Ecol Prog Ser 149:43-59

Eggleston DB, Grover JJ, Lipcius RN (1998) Ontogenetic diet shifts in Nassau grouper: trophic linkages and predatory impact. Bull Mar Sci 63:111-126

> Francis RC, Hixon MA, Clarke ME, Murawski SA, Ralston S (2007) Fisheries management: ten commandments for ecosystem-based fisheries scientists. Fisheries 32: $217-233$

Heemstra PC, Randall JE (1993) FAO species catalogue. Vol. 16. Groupers of the world (Family Serranidae, Subfamily Epinephelinae). FAO, Rome

$>$ Heithaus MR, Frid A, Wirsing AJ, Worm B (2008) Predicting ecological consequences of marine top predator declines. Trends Ecol Evol 23:202-210

- Hixon MA, Carr MH (1997) Synergistic predation, density dependence, and population regulation in marine fish. Science 277:946-949

Hixon MA, Jones GP (2005) Competition, predation, and density-dependent mortality in demersal marine fishes. Ecology $86: 2847-2859$ 
Hixon MA, Pacala SW, Sandin SA (2002) Population regulation: historical context and contemporary challenges of open vs. closed systems. Ecology 83:1490-1508

> Jackson JBC, Kirby MX, Berger WH, Bjorndal KA and others (2001) Historical overfishing and the recent collapse of coastal ecosystems. Science 293:629-638

Knowlton N (2004) Multiple 'stable' states and the conservation of marine ecosystems. Prog Oceanogr 60:387-396

Lawton JH, Brown VK (1993) Redundancy in ecosystems. In: Schulze ED, Mooney HA (eds) Biodiversity and ecosystem function. Springer-Verlag, Berlin, p 255-270

Loreau M (2004) Does functional redundancy exist? Oikos 104:606-611

Mora C (2008) A clear human footprint in the coral reefs of the Caribbean. Proc R Soc Lond B Biol Sci 275:767-773

Mumby PJ, Harborne AR, Williams J, Kappel CV and others (2007) Trophic cascade facilitates coral recruitment in a marine reserve. Proc Natl Acad Sci USA 104:8362-8367

Myers RA, Worm B (2003) Rapid worldwide depletion of predatory fish communities. Nature 423:280-283

O'Connor NE, Grabowski JH, Ladwig LM, Bruno JF (2008) Simulated predator extinctions: predator identity affects survival and recruitment of oysters. Ecology 89:428-438

Paine RT (1966) Food web complexity and species diversity. Am Nat 100:65-75

Pauly D, Christensen V, Dalsgaard J, Froese R, Torres F (1998) Fishing down marine food webs. Science 279: 860-863

Polis GA, Strong DR (1996) Food web complexity and community dynamics. Am Nat 147:813-846

Editorial responsibility: Romuald Lipcius,

Gloucester Point, Virginia, USA
Randall JE (1967) Food habits of reef fishes of the West Indies. Stud Trop Oceanogr 5:665-847

Sih A, Englund G, Wooster D (1998) Emergent impacts of multiple predators on prey. Trends Ecol Evol 13:350-355

Solan M, Raffaelli DG, Paterson DM, White PCL, Pierce GJ (2006) Marine biodiversity and ecosystem function: empirical approaches and future research needs. Mar Ecol Prog Ser 311:175-309

Stallings CD (2008) Indirect effects of an exploited predator on recruitment of coral-reef fishes. Ecology 89:2090-2095

Stallings CD (in press) Fishery-independent data reveal negative effect of human population density on Caribbean predatory fish communities. PLoS ONE

Thorrold SR, Shenker JM, Mojica R Jr, Maddox ED, Wishinski E (1994) Temporal patterns in the larval supply of summer-recruiting reef fishes to Lee Stocking Island, Bahamas. Mar Ecol Prog Ser 112:75-86

- Vance-Chalcraft HD, Rosenheim JA, Vonesh JR, Osenberg CW, Sih A (2007) The influence of intraguild predation on prey suppression and prey release: a meta-analysis. Ecology 88:2689-2696

Ward P, Myers RA (2005) Shifts in open-ocean fish communities coinciding with the commencement of commercial fishing. Ecology 86:835-847

- White JW (2007) Spatially correlated recruitment of a marine predator and its prey shapes the large-scale pattern of density-dependent prey mortality. Ecol Lett 10: 1054-1065

Y Yap HT (2009) Local changes in community diversity after coral transplantation. Mar Ecol Prog Ser 374:33-41

Submitted: January 14, 2008; Accepted: March 9, 2009

Proofs received from author(s): April 22, 2009 